\title{
Variation in shoot organization of Cynodon dactylon: is it the grass with an opposite phyllotaxy?
}

\author{
Akitoshi Iwamoto, Tomohiko Inoue \\ Department of Biology, Tokyo Gakugei University, 4-1-1 Nukui-kita-machi, Koganei-shi, Tokyo 184-8501, Japan \\ Author for correspondence: A. Iwamoto, akitoshi@u-gakugei.ac.jp
}

Summary: Although grasses basically have a distichous phyllotaxy, the vegetative shoots of Cynodon dactylon seem to show two types of phyllotaxy, including opposite phyllotaxy. These phyllotaxies, however, may be formed by internodal growth after initiation of leaf primordia. To determine the initial phyllotaxy of $C$. dactylon, we observed the development and anatomy of the shoot apices of vertical and creeping vegetative shoots. The former seem to have an opposite phyllotaxy and the latter have a triserial phyllotaxy. In both vertical and creeping shoots, the initiation pattern of the leaf primordia was clearly distichous and the leaf primordia on shoot apices were more concentrated than those of other grasses. Therefore, apparent phyllotaxies, including opposite phyllotaxy, can be derived in C. dactylon from the regulation of internodal growth after concentrated initiation of distichous leaf primordia.

Key words: Cynodon dactylon, vegetative development, opposite phyllotaxy, vertical shoot, rhizome

\section{INTRODUCTION}

Cynodon dactylon (L.) Pers. is a perennial grass common in warm climates and used for forage and turf. The species is regarded as one of the most troublesome weeds (Holm et al. 1977), because the plant spreads so rapidly and widely that a $15 \mathrm{~cm}$-length sprig can grow to cover a sod area of up to $25 \mathrm{~m}^{2}$ after 2.5 years, and fragmented creeping shoots show a high propagative capacity (Horowitz 1972a, b).

In the plants of the Poaceae, with few exceptions, leaves are inserted distichously (Dahlgren et al. 1985). C. dactylon, however, shows two types of phyllotaxy for its vegetative shoots, including the "opposite" arrangement (Fig. 1). In the stage of creeping shoot, a vegetative shoot apparently has three concentrated leaves at one node (triserial) (Fig. 1a), while leaves appear to be oppositely arranged in a vertical shoot derived from the creeping shoot (Fig. 1b).

Most other turf grass species have a normal distichous (Agrostis plaustris, Poa pratensis, Festuca arundinacea, F. rubura, and Digitaria decumbens) or triserial phyllotaxy (Zoysia japonica and its hybrids) (Stiff and Powell, 1974). Only Stenotaphrum secundatum and Cynodon dactylon have two types of phyllotaxy including "opposite" phyllotaxy. Therefore, the morphological features of Cynodon dactylon are enigmatic, and the Japanese name of this species, "Gyogi-shiba", which means "a grass with orderly leaf arrangement" (Makino 2008), should be derived from the orderly "opposite" phyllotaxy in a vertical shoot.

On the other hand, observation of the development and anatomy of this species is necessary for elucidating the true phyllotaxy of this enigmatic grass, but this remains to be undertaken. This article focuses on the shoot apices of creeping and vertical shoots of $C$. dactylon and aims to observe the precise developments of each phyllotactic pattern and indicate the differences between them.
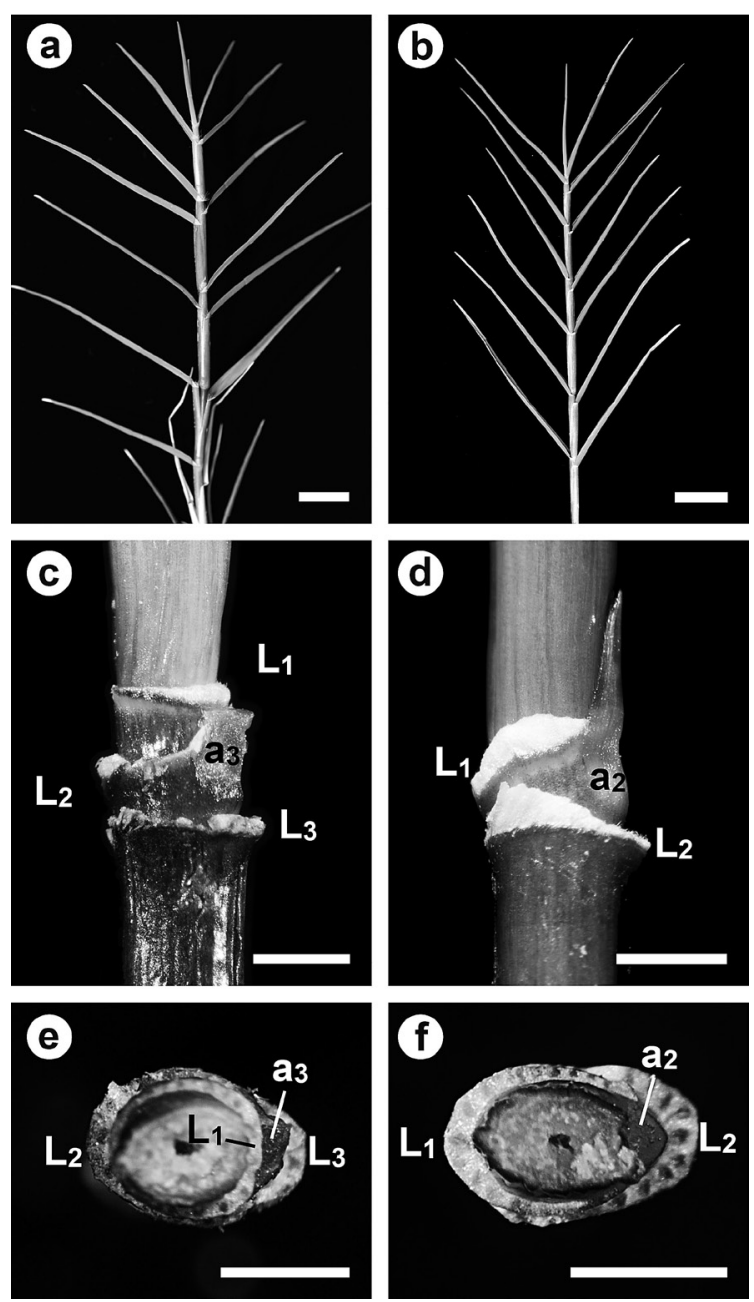

Figure 1 a-f Vegetative shoots of Cynodon dactylon. Two types of phyllotaxies are shown. a Creeping shoot showing "triserial" phyllotaxy. b Vertical shoot with "opposite" phyllotaxy. c Nodes of creeping shoot where leaves were removed. $\mathbf{d}$ Nodes of vertical shoot where leaves were removed. e The nodes in Fig. 1c seen from above. The part of stem above the nodes was removed. $\mathbf{f}$ The nodes in Fig. 1d seen from above. The part of stem above the nodes was removed. a = axillary bud. $\mathrm{L}=$ leaf. Numbers with abbreviations are the initiation order. Scale bars $=1 \mathrm{~cm}$. 


\section{MATERIALS AND METHODS}

Plant material

Living plants of Cynodon dactylon (L.) Pers. were collected from the banks of the Tama River, in Fuchu-shi, Tokyo and cultivated at Tokyo Gakugei University. Voucher specimens are also housed at the latter.

\section{SEM and anatomical observation}

For scanning electron microscopic (SEM) observations of the development of shoot apices, materials fixed with FAA (absolute ethanol, 50\%; glacial acetic acid, $5 \%$; formalin, $5 \%$; and water $40 \%$ ) were used. The fixed materials were dehydrated in a graded ethanol series, after which the ethanol was replaced with isoamyl acetate. The samples were then dried with a critical point dryer (JCPD-5, JEOL, Tokyo, Japan). Dried samples were coated with $\mathrm{Au} / \mathrm{Pd}$ using a sputter coater (Ion Coater JFC-1100, JEOL, Tokyo, Japan), and observed with a JSM-5800LV SEM (JEOL, Tokyo, Japan) at $5 \mathrm{kV}$. For anatomical observations, the materials fixed with FAA were dehydrated in a graded ethanol series, and embedded in Technovit 7100 (Heraeus Kulzer GmbH, Wehrheim, Germany). The embedded blocks were cut into $3-\mu \mathrm{m}$-thick sections and stained with solutions of safranin and toluidine blue (Ruzin,1999).

\section{RESULTS}

\section{Leaf arrangement at node}

The observation of nodes of vertical shoot of $C$. dactylon, where leaves were removed, revealed that the bases of triserial leaves were very close to each other, but they were not formed at the same node (Fig. 1c). Only one axillary bud of these three leaves developed, which was subtended by the lowest one. The overview of these nodes showed that these three leaves had a distichous phyllotaxy (Fig. 1e).

The observation of nodes of creeping shoot also revealed that the leaf bases of two leaves were very close, but they were not formed at the same node (Fig. 1d). The overview showed that the leaves of creeping shoot had a distichous phyllotaxy (Fig. $1 \mathrm{f}$ ).

Therefore, the apparent "triserial" and "opposite" phyllotaxies of $C$. dactylon are not triserial and opposite but alternate.

\section{Development of shoot apex}

The observation of vertical shoots, where some leaves which grew to a certain size were removed, revealed that a caveshaped leaf primordium covered the shoot apex (Fig. 2a). The shoot apex was observable after the dissection of the covering primordia, however most of the apex was still covered by another cave-shaped leaf primordium (Fig. 2b). After dissecting the leaf primordia, the whole shoot apex can be observed with two youngest leaf primordia (Fig. 2c). Though the second youngest primordium did not develop into a cave shape, its marginal part developed well, and it is difficult to find a clear boundary between its marginal part and the youngest leaf primordium.

Only the apices of vertical shoots are shown here, but those of creeping shoots were almost identical.

\section{Anatomy of shoot apex}

Longitudinal sections revealed that the shoot apex of a vertical shoot is small and has only one distinct tunica layer (Figs. 3a, b). Leaf primordia around the shoot apex were very concentrated. The youngest leaf primordium $\left(\mathrm{L}_{1}\right)$ initiated just above the marginal part of the second youngest leaf primordium $\left(\mathrm{l}_{2}\right)$, and the boundary between them was ambiguous (Fig. 3a). At a slightly later stage, $\mathrm{L}_{1}$ developed and could be distinguished from $l_{2}$, though the boundary was still not so clear (Fig. 3b). The node where $\mathrm{L}_{1}$ was produced is clearly different from that of $l_{2}$.

The shoot apices of creeping shoots are also small and have only one tunica layer (Figs. 4a, b). Leaf primordia are arranged as compactly as those of vertical shoots. In particular, $\mathrm{L}_{1}$ was immediately adjacent to $l_{2}$ at the earliest stage (Fig. 4a). The boundary between them became clear as $\mathrm{L}_{1}$ developed (Fig. 4b).

\section{DISCUSSION}

While there is a distinct difference between apparent phyllotaxies in vertical shoots and creeping shoots, the development of their shoot apices are almost identical. Both of their developments clearly show that young leaf primordia initiate distichously, therefore, two types of phyllotaxies in $C$.
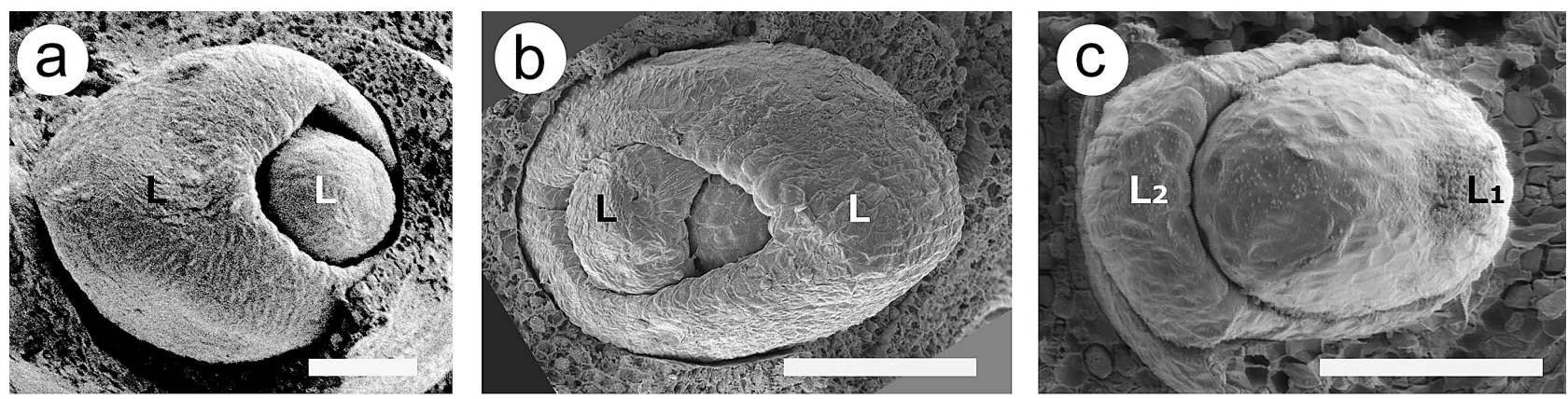

Figure 2 a-c Shoot apices of vertical vegetative shoots of Cynodon dactylon (SEM micrograph). a Shoot apex with mature leaves removed. b Shoot apex with some of the covering leaf primordia in (a) removed. The apex is still covered with one leaf primordium. $\mathbf{c}$ Shoot apex with all of the covering leaf primordia removed. $\mathrm{L}=$ leaf primordium. Scale bars $=50 \mu \mathrm{m}$. 


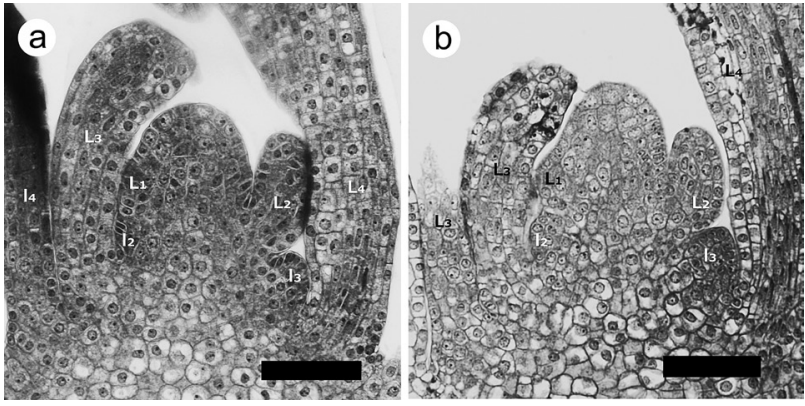

Figure 3 a, b Longitudinal sections of vertical vegetative shoots (Technovit sections). a Shoot apex with four leaf primordia. Note that the central part of each leaf primordium is adjacent to the marginal part of the next leaf primordium. b Shoot apex with youngest leaf primordium more developed than that in (a). $\mathrm{L}=$ leaf primordium; $1=$ marginal part of leaf primordium. Numbers with abbreviations are the initiation order Scale bars $=50 \mu \mathrm{m}$

dactylon, namely, apparent triserial phyllotaxy and opposite phyllotaxy should be derived from the same distichous initiation of leaf primordia. Our observation also indicates that the plastchrons in both vertical shoots and creeping shoots are very short. Therefore, the regulation of internodal growth and/ or some distortions after initiation may result in two types of phyllotaxy in $C$. dactylon. The measurements of elongation rates of internodes in both of vertical and creeping shoot are necessary to confirm that there is such inter nodal growth regulation. We plan to measure the elongation rates of epidermal cells of inter nodes in both type shoots using the kinematic method we successfully adopted for root growth (Iwamoto et al. 2006).

The development of vegetative shoot apices of some Poaceae species has been observed in detail (Abbe and Phinney 1951, Abbe et al. 1951, Ledin 1954, Opatrn et al. 1964, Rogan and Smith 1974, Steffensen 1968). Compared with these species, C. dactylon has more concentrated leaf primordia on the shoot apex, although Agropyron repens does show a similar concentrated arrangement on the shoot apex only at a mature stage (Rogan and Smith 1974). This arrangement in Agropyron repens could, however, be caused by the decline of shoot extension growth due to age, and this species actually has longer plastchrons at younger stages (Rogan and Smith 1974). We thereby concluded that the concentrated arrangement of leaf primordia on the shoot apex is a specific morphological character of $C$. dactylon, which may result in the specific phyllotactic pattern of this species.

\section{ACKNOWLEDGEMENTS}

We would like to thank Dr. Hidehisa Koba for his helpful advice in this study. This work was partly supported by: a Grant-in-Aid for Scientific Research on Innovative Areas (no. 23119505 to $\mathrm{AI})$.

\section{REFERENCES}

Abbe, E., and Phinney, B. (1951) The growth of the shoot apex in maize: external features. Am J Bot 38: 737-744.

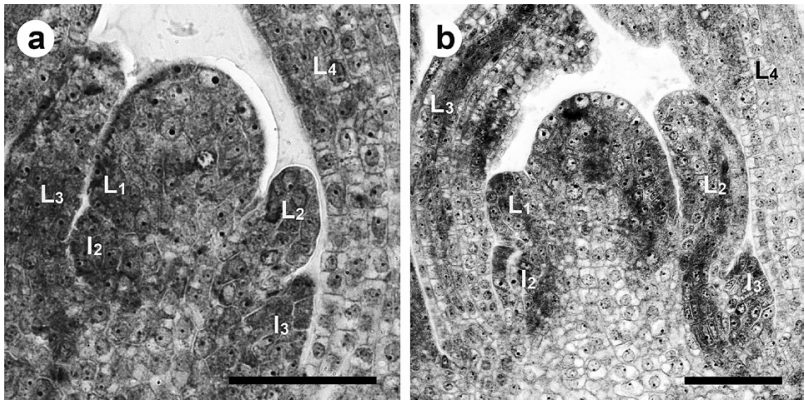

Figure 4 a, b Longitudinal sections of creeping shoots (Technovit sections). a Shoot apex with four leaf primordia. b Shoot apex with youngest leaf primordium more developed than that in (a). Abbreviations are the same as those in Fig. 3. Scale bars $=50 \mu \mathrm{m}$.

Abbe, E., Phinney, B., and Baer, D. (1951) The growth of the shoot apex in maize: internal features. Am J Bot 38: 744-751.

Dahlgren, R. M. T., Clifford, H. T., and Yeo, P. F. (1985) The families of the monocotyledons. Structure, evolution, and taxonomy, SpringerVerlag, Berlin.

Holm, L. G., Plucknett, D. L., Pancho, J. V., and Herberger, J. P. (1977) The world's worst weeds. Distribution and biology, University Press of Hawaii.

Horowitz, M. (1972a) Development of Cynodon dactylon (L.) Pers. Weed Res 12: 207-220

Horowitz, M. (1972b) Spatial growth of Cynodon dactylon (L.) Pers. Weed Res 12: 373-383.

Iwamoto, A., Satoh, D., Furutani, M., Maruyama, S., Ohba, H., and Sugiyama, M. (2006) Insight into the basis of root growth in Arabidopsis thaliana provided by a simple mathematical model. $J$ Plant Res 119: 85-93.

Ledin, R. B. (1954) The vegetative shoot apex of Zea mays. Am J Bot 41: 11-17.

Makino, T. (2008) New Makino's illustrated flora of Japan, Hokuryukan, Tokyo.

Opatrn, J., Seidlov, F., and Bene, K. (1964) The anatomy of the shoot apex of wheat (Triticutn aestivum L.) during transition from the vegetative to the reproductive state and the determination of the primordia. Biol Plant 6: 219-225.

Rogan, P., and Smith, D. (1974) The development of the shoot apex of Agropyron repens (L.) Beauv. Ann Bot 38: 967.

Ruzin, S. E. (1999) Plant microtechnique and microscopy, Oxford, New York.

Steffensen, D. M. (1968) A reconstruction of cell development in the shoot apex of maize. Am J Bot 55: 354-369.

Stiff, M., and Powell, J. (1974) Stem anatomy of turfgrass. Crop Sci 14: 181-186.

Received: 6 Mar 2012 / Accepted : 20 January 2013 